\title{
Too good to be true
}

\author{
Bom demais para ser verdade
}

Francisco Cardoso

Universidade Federal de

Minas Gerais, Departamento

de Medicina Interna, Serviço

de Neurologia, Unidade de

Distúrbios do Movimento,

Belo Horizonte, MG, Brasil.

Correspondence:

Francisco Cardoso;

Av Pasteur 89/1107; 30150-290

Belo Horizonte MG, Brasil;

E-mail: cardosofe@terra.com.br

Conflict of interest:

There is no conflict of

interest to declare.

Received 20 January 2018

Accepted 22 January 2018

\section{(c) BY}

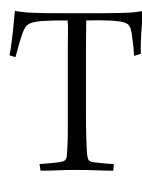

wo hundred and one years after the original description of Parkinson's disease (PD) ${ }^{1}$, its cause and pathogenesis remain to be determined. Over this period of time, many hypotheses have been suggested: an exclusively environmental condition caused by an, as of yet, unidentified toxin; a mitochondrial disorder; a lysosomal condition; a purely genetic disease; the result of an interplay of genetic and environmental disorder; and so $\mathrm{on}^{2}$. In the current issue of Arquivos, there is a timely and critical review by Gershanik of the involvement of alpha-synuclein (ASN) and the hypothesis that the disease starts in the gut ${ }^{3}$. According to the hypothesis, mutated ASN originated from the enteric nervous system reaches the dorsal motor nucleus of the vagus. The involvement of this nucleus characterizes Braak PD stage I. From the dorsal motor nucleus of the vagus there is cranial spreading of ASN resulting in stages II through VI. Interestingly, in chapter IV of his essay, Parkinson suggested that the condition he was describing was related to "a diseased state of the medulla spinalis, in that part which is contained in the canal, formed by the superior cervical vertebrae, and extending, as the disease proceeds, to the medulla oblongata." ${ }^{1}$. Although the hypothesis is elegant and attractive, as Gershanik rightly points out, there are several issues that cast doubt on its validity. In the following paragraphs, I will also discuss other potential caveats of this hypothesis.

Firstly, a critical prerequisite of this hypothesis is to accept that ASN has a prion-like behavior. According to this hypothesis, mutated ASN is capable of inducing wild ASN to undergo mutation. As it happens in prion diseases, this mechanism would lead to the spreading of pathology in the brain. Although there is evidence in support of this, particularly in experimental models, many experts argue that the hypothesis overstretches the comparison ${ }^{4}$. Another critical feature of the hypothesis is the existence of ASN in the colonic mucosa. Unfortunately, the picture of this issue is far from clear: many studies have failed to differentiate the colonic mucosa of PD patients from controls regarding the presence of $\mathrm{ASN}^{5}$.

If we accept that indeed there is uptake by the vagus nerve of mutated ASN originated from the gut, there still remain several inconsistencies in the hypothesis. The first one is related to epidemiological studies. Two surveys of large numbers of individuals from Sweden and Denmark have shown that truncal vagotomy decreases the likelihood of the future development of $\mathrm{PD}^{6,7}$. However, the effect size is very modest. For instance, in the Swedish study, the hazard ratio of the incidence of PD in patients who underwent truncal vagotomy, in comparison with control individuals, was 0.78 . There are several potential explanations for this result. The first is the possibility that the pathogenic process starts very early in life before the time of the vagotomy. This would allow the brainstem to receive ASN before the procedure, reducing the benefit of a truncal vagotomy later in life. A second possibility is that the gut is just one of multiple sources of ASN that can reach the brainstem.

There are also clinical shortcomings in the gut hypothesis. A significant number of PD patients do not have constipation as a premotor manifestation, suggesting that the dorsal motor nucleus of the vagus is spared in these individuals. Rather, these patients may have hyposmia, depression and REM sleep behavior disorders, which are related to, respectively, the olfactory bulb, the raphe nuclei and the sublaterodorsal nucleus 8 . More recently, studies including the use of cluster analysis show that many individuals do not conform to the Braak hypothesis. These patients may not develop hyposmia, others will have olfaction impairment 
simply later in the course of the disease, and several of them have cognitive and/or behavioral changes at the onset of the illness ${ }^{9}$. Once again, these findings indicate that PD can start in distinct sites of the CNS.

Finally, the gut theory does not take into account the remarkable advancement of understanding of the genetics of PD. In at least $10 \%$ of patients the disease is determined exclusively or almost exclusively by genetic factors. Moreover, in the remaining, apparently sporadic cases, genetic factors also play an important part. One good example of the interplay between genetic and environmental factors is the presence of one mutated allele of the glucocerebrosidase gene. This is regarded as the most important risk factor for the development of $\mathrm{PD}^{10}$. The mutation leads to impairment of lysosomal function in the brain and other extraneural areas, not specifically related to the gut. However, there are authors who attempt to reconcile the gut hypothesis with genetic factors. In one study, there was an association between variants in genes that encode peptidoglycan recognition proteins and the risk of PD. Of note, peptidoglycan recognition proteins are involved in the regulation of the immune response to bacteria involved in changes of gut permeability. This is a, presumably critical, step in the initiation of pathological processes leading to the migration of ASN toward the brainstem ${ }^{11}$. Unfortunately, these findings have not yet been replicated.

In conclusion, the theory that the pathogenesis of PD starts in the enteric nervous system is attractive, has internal consistency and is supported by some indirect evidence. Nevertheless, there are features related to the molecular biology of ASN, as well as the epidemiology, clinical features and genetics of PD, that cast serious doubts about its validity.

\section{References}

1. Parkinson J. An essay on the Shaking Palsy. London: Whittingham and Rowland; 1817.

2. Obeso JA, Stamelou M, Goetz CG, Poewe W, Lang AE, Weintraub D et al. Past, present, and future of Parkinson's disease: a special essay on the 200th Anniversary of the Shaking Palsy. Mov Disord. 2017 Sep;32(9):1264-310. https://doi.org/10.1002/mds.27115

3. Gershanik O. Does Parkinson's disease start in the gut? Arq Neuropsiquiatr. 2018;76(2):67-70. https://doi.org/10.1590/0004-282X20170188

4. Fung VS, Kordower JH. Parkinson's disease and prion disease: straining the comparison. Mov Disord. 2015 Nov;30(13):1727. https://doi.org/10.1002/mds.26437

5. Visanji NP, Marras C, Hazrati LN, Liu LW, Lang AE. Alimentary, my dear Watson? The challenges of enteric $\alpha$-synuclein as a Parkinson's disease biomarker. Mov Disord. 2014 Apr;29(4):444-50. https://doi.org/10.1002/mds.25789

6. Svensson E, Horváth-Puhó E, Thomsen RW, Djurhuus JC, Pedersen L, Borghammer P et al. Vagotomy and subsequent risk of Parkinson's disease. Ann Neurol. 2015 Oct;78(4):522-9. https://doi.org/10.1002/ana.24448

7. Liu B, Fang F, Pedersen NL, Tillander A, Ludvigsson JF, Ekbom A et al. Vagotomy and Parkinson disease: A Swedish register-based matched-cohort study. Neurology. 2017 May;88(21):1996-2002. https://doi.org/10.1212/WNL.0000000000003961

8. Berg D, Postuma RB, Adler CH, Bloem BR, Chan P, Dubois B et al. MDS research criteria for prodromal Parkinson's disease. Mov Disord. 2015 Oct;30(12):1600-11. https://doi.org/10.1002/mds.26431

9. Marras C, Chaudhuri KR. Nonmotor features of Parkinson's disease subtypes. Mov Disord. 2016 Aug;31(8):1095-102. https://doi.org/10.1002/mds.26510

10. Standaert DG. What would Dr. James parkinson think today? Mutations in beta-glucocerebrosidase and risk of Parkinson's disease. Mov Disord. 2017 Oct;32(10):1341-2. https://doi.org/10.1002/mds.27206

11. Goldman SM, Kamel F, Ross GW, Jewell SA, Marras C, Hoppin JA et al. Peptidoglycan recognition protein genes and risk of Parkinson's disease. Mov Disord. 2014 Aug;29(9):1171-80. https://doi.org/10.1002/mds.25895 